\title{
Resources Sharing Mechanism of University Clusters under the Policy of Beijing-Tianjin-Hebei Collaborative Development
}

\author{
Wang $\mathrm{Yu}^{*}$ \\ School of Humanities, \\ Tianjin University of Finance and Economics \\ Tianjin, China \\ *Corresponding author
}

\author{
Bao Jie \\ School of Humanities, \\ Tianjin University of Finance and Economics \\ Tianjin, China
}

\begin{abstract}
The collaborative development of Beijing, Tianjin and Hebei Province has been implemented in an all-round way. With the coordinated development of university clusters, infrastructure construction and interconnection have been accelerated. This paper aims to explore the current layout of the Beijing-Tianjin-Hebei university clusters in resources sharing through quantitative and analytic approaches. Positive contributions to the new collaborative development of university clusters have been made in aspects of interregional government cooperation, intercollegiate cluster development and interscholastic opening-up policy.
\end{abstract}

Keywords-Resources sharing mechanism; University clusters; Beijing-Tianjin-Hebei

\section{INTRODUCTION}

The cluster development of cities is a powerful way to boost comprehensive national strength. Beijing, Tianjin and Hebei locate in the heartland of Bohai-rim, making up the most powerful and dynamic region in North China. The GDP of this region accounted for 10 percent of the whole country in 2015 according to the data from State Statistic Bureau. In 2014, the Chinese Premier Li Keqiang proposed the scheme of BeijingTianjin-Hebei Integration. A year later in 2015, the Outline of Collaborative Development of Beijing, Tianjin and Hebei Province has been issued and implemented as a national plan, aiming to relieve the "non-capital" function of Beijing and promote the coordinated and integrated development of Beijin, Tianjin and Hebei. Higher education, which provides human resources support and intellectual support, is one of the greatest driving forces for the implementation of the national policy. Regional higher education cooperation is an important measure for regional economic development and social stability [1]. By building an effective sharing mechanism, it will take a leading role in the new developing mode of Beijing-Tianjin-Hebei integration which is dominated by the government and driven by science and education [2]

This research was financially supported by Tianjin Philosophy and Socia Science Foundation, China (TJYY17-025).

\section{HINDERING FACTORS FOR EFFECTIVE RESOURCE SHARING}

First, Beijing, Tianjin and Hebei have different development levels in terms of higher education due to geographical, historical, economic and cultural reasons. Beijing, as the capital city of China, has the highest level of higher education. Tianjin, being the economic center of Bohai-rim as well as the most important port city of North China, also has a relatively high level of higher education. Compared with these two cities, Hebei is clearly at a disadvantage with the largest total population and the fewest key universities. Followed is a table that shows the distribution of higher education institutions in Beijing, Tianjin and Hebei.

\section{A. Maintaining the Integrity of the Specifications}

The template is used to format your paper and style the text. All margins, column widths, line spaces, and text fonts are prescribed; please do not alter them. You may note peculiarities. For example, the head margin in this template measures proportionately more than is customary. This measurement and others are deliberate, using specifications that anticipate your paper as one part of the entire proceedings, and not as an independent document. Please do not revise any of the current designations.

TABLE I DISTRIBUTION OF HIGHER EDUCATION INSTITUTIONS IN BEIJING, TIANJIN AND HEBEI (2017) (INDEPENDENT COLLEGE AND JUNIOR

\begin{tabular}{|c|c|c|c|c|}
\hline Location & $\begin{array}{c}\text { Total } \\
\text { Quantity }\end{array}$ & $\begin{array}{c}\mathbf{2 1 1} \\
\text { Institutions }\end{array}$ & $\begin{array}{c}\mathbf{9 8 5} \\
\text { Institutions }\end{array}$ & $\begin{array}{c}\text { Institutions under } \\
\text { Ministry of Education }\end{array}$ \\
\hline Beijing & 91 & 26 & 9 & 25 \\
\hline Tianjin & 57 & 3 & 2 & 2 \\
\hline Hebei & 122 & 1 & 0 & 0 \\
\hline
\end{tabular}

Second, there are huge gaps between ordinary universities and core universities, public universities and private universities. Core universities have better human resource, material resources and intangible resources. Human resources refer to teaching and research personnel. Material resources refer to material possessions including libraries, laboratories, university-run enterprises, public service facilities and so on. 
Intangible resources refer to patents, trademarks, copyrights as well as school reputation, recruitment channel, employment channel and so on[3]. Take human resources, one of the key indicators of a university's comprehensive power, for example, great differences can be seen between key universities and ordinary universities. Followed are tables that show the distribution of academician of Chinese Academy of Science, academician of Chinese Academy of Engineering, and Chanjiang Scholar in higher education institutions in Beijing, Tianjin and Hebei.

TABLE II Distribution of ACAdEMician OF Chinese ACAdEMy of SCIENCE (2015)

\begin{tabular}{|c|c|c|c|}
\hline Name & $\begin{array}{c}\text { Number } \\
\text { of Academician }\end{array}$ & $\begin{array}{l}985 \\
/ 211\end{array}$ & Location \\
\hline Beijing University & 34 & 985 & Beijing \\
\hline Tsinghua University & 25 & 985 & Beijing \\
\hline Nankai University & 8 & 985 & Tianjin \\
\hline China University of Geosciences & 6 & 211 & Beijing \\
\hline Beijing Normal University & 5 & 985 & Beijing \\
\hline Tianjin University & 4 & 985 & Tianjin \\
\hline China Agricultural University & 4 & 985 & Beijing \\
\hline Peking Union Medical College & 4 & 1 & Beijing \\
\hline Beihang University & 2 & 985 & Beijing \\
\hline China University of Petroleum & 2 & 211 & Beijing \\
\hline University of Science and Technology Beijing & 2 & 211 & Beijing \\
\hline Beijing Jiaotong University & 2 & 211 & Beijing \\
\hline Capital Medical University & 2 & 1 & Beijing \\
\hline Beijing University of Technology & 2 & 211 & Beijing \\
\hline Hebei University & 2 & 1 & Hebei \\
\hline Beijing Institute of Technology & 1 & 985 & Beijing \\
\hline China University of Mining and Technology & 1 & 211 & Beijing \\
\hline Hebei Normal University & 1 & $\frac{1}{1}$ & Hebei \\
\hline
\end{tabular}

(Source of data: Ministry of Education website)

TABLE III Distribution of ACADEMICIAN OF ChINESE ACADEMy of ENGINEERING (2015)

\begin{tabular}{|c|c|c|c|}
\hline Name & Number of Academician & $\begin{array}{c}985 \\
/ 211 \\
\end{array}$ & Location \\
\hline Tsinghua University & 34 & 985 & Beijing \\
\hline Peking Union Medical College & 21 & 1 & Beijing \\
\hline Beijing University & 10 & 985 & Beijing \\
\hline Beihang University & 10 & 985 & Beijing \\
\hline China Agricultural University & 9 & 985 & Beijing \\
\hline Tianjin University & 8 & 985 & Tianjin \\
\hline Beijing Institute of Technology & 5 & 985 & Beijing \\
\hline Beijing Forestry University & 5 & 211 & Beijing \\
\hline University of Science and Technology Beijing & 4 & 211 & Beijing \\
\hline Capital Medical University & 4 & 1 & Beijing \\
\hline Beijing University of Posts and Telecommunications & 3 & 211 & Beijing \\
\hline China University of Petroleum & 2 & 211 & Beijing \\
\hline Beijing Jiaotong University & 2 & 211 & Beijing \\
\hline Beijing University of Chemical Technology & 2 & 211 & Beijing \\
\hline Beijing University of Technology & 2 & 211 & Beijing \\
\hline Tianjin Medical University & 2 & 211 & Tianjin \\
\hline Tianjin University of Traditional Chinese Medicine & 2 & / & Tianjin \\
\hline Hebei Medical University & 2 & 1 & Hebei \\
\hline Nankai University & 1 & 985 & Tianjin \\
\hline Beijing Normal University & 1 & 985 & Beijing \\
\hline China University of Mining and Technology & 1 & 211 & Beijing \\
\hline Beijing University of Chinese Medicine & 1 & 211 & Beijing \\
\hline Beijing Technology and Business University & 1 & l & Beijing \\
\hline
\end{tabular}


TABLE IV DISTRIBUTION OF CHANG JIANG SCHOLARS (2015)

\begin{tabular}{|c|c|c|c|}
\hline Name & Number of Academician & $\begin{array}{c}985 \\
/ 211\end{array}$ & Location \\
\hline Tsinghua University & 140 & 985 & Beijing \\
\hline Beijing University & 138 & 985 & Beijing \\
\hline Beihang University & 41 & 985 & Beijing \\
\hline Nankai University & 37 & 985 & Tianjin \\
\hline Beijing Normal University & 35 & 985 & Beijing \\
\hline Remin University of China & 32 & 985 & Beijing \\
\hline Tianjin University & 28 & 985 & Tianjin \\
\hline China Agricultural University & 23 & 985 & Beijing \\
\hline Beijing Institute of Technology & 21 & 985 & Beijing \\
\hline Peking Union Medical College & 18 & 1 & Beijing \\
\hline University of Science and Technology Beijing & 12 & 211 & Beijing \\
\hline Beijing University of Chemical University & 11 & 211 & Beijing \\
\hline Beijing University of Petroleum & 10 & 211 & Beijing \\
\hline Beijing Jiaotong University & 10 & 211 & Beijing \\
\hline Beijing University of Technology & 9 & 211 & Beijing \\
\hline Yanshan University & 6 & 1 & Hebei \\
\hline Capital Medical University & 5 & 1 & Beijing \\
\hline China University of Mining and Technology & 5 & 211 & Beijing \\
\hline Beijing University of Posts and Telecommunications & 4 & 211 & Beijing \\
\hline Hebei University of Technology & 1 & 211 & Hebei \\
\hline Minzu University of China & 1 & 985 & Beijing \\
\hline University of International Business and Economics & 1 & 211 & Beijing \\
\hline Beijing University of Civil Engineering and Architecture & 1 & / & Beijing \\
\hline
\end{tabular}

Table II, III and IV show that high-quality teacher resources mainly exist in 211 and 985 universities while ordinary universities have far less excellent human resources. Besides human resources, ordinary and private universities are also confronted with the problem of inadequate funds, incomplete infrastructures and disadvantaged channels of enrollment and employment. Based on the great discrepancy, advantaged universities are not always likely to share their advanced resources with ordinary universities on accounts that ordinary universities do not have much to offer.

\section{STRATEGIES FOR EFFECTIVE SHARING MECHANISM}

\section{A. Interregional government cooperation}

Government is the main body to provide resources for higher education. Local governments have been trapped in the mindset of "minding its own business" and this has become one of the hindering factors for resource sharing [4]. The traditional development mode of Beijing, Tianjin and Hebei focuses more on competitive rather than cooperation. It is not uncommon for local governments to try to maintain their competitive edges in terms of higher education. However, with the implementation of Beijing-Tianjin-Hebei integration as a national policy, coordinated and reciprocal development has become a must. To promote resource sharing in regional higher education institutions, administrative bulwark should be broken down and the concept of administrative division should be downplayed. Governments of Beijing, Tianjin and Hebei should strengthen their cooperation and try work out a long term mechanism to promote resource sharing among institutions in these areas. A Certain number of favorable policies due to intergovernmental cooperation have already been made to promote deeper sharing and cooperation.

In November, 2009, the paper Six Cooperation intention reached by Education Commission of Beijing, Tianjin and Hebei on Higher Education Development put forward a coordination mechanism of regular discussion on cooperation and work focus. In April of 2011, Governments of Beijing, Tianjin and Hebei signed the Talent Cooperation Framework Protocol in Beijing-Tianjin-Hebei region, aiming to realize the free flow of talent and the optimization of layout through policy coordination, coherent government system and connective services [5]. In February of 2017, Work Plan for Higher Education Coordination of Beijing-Tianjin-Hebei Integration in "13th Five-Year has been issued. To secure and supervise the implementation of all these favorable policies, local governments should work beyond the restriction of administrative division and set up a standing organization to deal with issues related to higher education coordination and resource sharing among institutions. 


\section{B. Intercollegiate cluster development}

Define Intercollegiate cluster development is a higher level of resource sharing. Cluster development of universities can benefit regional integrated development by realizing complementary advantages, promoting work-study combination and stimulating regional economy. By building university towns and education-research-production parks, not only the flow and sharing of resources but also accumulative effect can be achieved. Beijing, Tianjin and Hebei adjoin geographically, which provides advantageous pre-condition for cluster development. The cluster development of universities and the cluster development of Beijing, Tianjin and Hebei complement each other. One the one hand, city agglomeration has the power to attract high-quality education resources from home and abroad. One the other hand, cluster of universities and cluster of cities drive each other and promote each other [6]. Because of development level of higher education in Beijing, Tianjin and Hebei, key universities in Beijing could remove some of its resources into Tianjin and Hebei by building chain universities. In recent years, quite a few university towns were built in Tianjin. Haihe Education Park and Health Care Industry Park were built to supplement the traditional university towns in Tianjin. Hebei has also built oriental college town. So these two areas are fully capable of undertaking the spillover of talents and resources from Beijing. In these big university towns, research centers and enterprises training bases should also be built to promote the combination and integration of education, research and production.

\section{Interscholastic opening-up policy}

National Program for Medium-Long Term Educational Reform and Development, 2010-2020 has put forward the requirement on educational reform and proposed the idea of building open education system [7]. In 2016, the Ministry of Education in China proposed the idea of "building opening-up university system with Chinese characteristics in this new era" in the government paper named Opinions on Running Open Universities [8]. Opening-up policy of university clusters refers to a new mode of higher education which is assessable to all learners by integrating educational resources with the help of modern technology [9]. It is an effective and economical way to achieve resource sharing. At present, Beijing has already set up Beijing Opening-up Universities. Tianjin and Hebei are also positively preparing for the groundwork of opening-up universities. With the perfection of Central Radio and TV University System, regional opening-up policy of BeijingTianjin-Hebei region is gradually taking shape. By applying advanced modern technology to build up on-line and off line to further education in universities, sharing resource in BeijinTianjin-Hebei region is expected to extend to a larger scale.

\section{CONCLUSION}

With the coordinated develops of university clusters, a platform for exchange and cooperation of regional universities to facilitate sharing resources and project cooperation has been built. A collaborative innovation community will help BeijinTianjin-Hebei universities go further in future. The new collaborative development of university clusters will display the regional resources transfer collaboration to provide a comprehensive and open innovation service platform, covering the resources that drive regional development, thus helping Beijin-Tianjin-Hebei universities to build a resource sharing center with regional influence.

\section{ACKNOWLEDGMENT}

This research was financially supported by Tianjin Philosophy and Social Science Foundation, China (TJYY17025).

\section{REFERENCES}

[1] Zanying Liu, Xingguo Liu, Enhancing cooperation for connotative development of higher education in Beijing-Tianjin-Hebei, J. Journal of Hebei University of Technology (Social Science Edition), vol. 4, pp.1317, 2013.

[2] Yan Wu, Xiaoyan Wang, Exploring the new development mode of Beijing-Tianjin-Hebei regional higher education, J. Chinese Higher Education Research, vol.8, pp. 1-7, 2010.

[3] Lingli Dong, Study of resource sharing of higher education in Nanjin, J. Social Sciences in Nanjing, vol.6, pp. 47-50, 1996.

[4] Jichang Yan, Investigation on the resource sharing mechanism of education, J. Distance Education in China, pp. 64, 2003.

[5] Bateer Chen, Qi Zhang, Coordinated development of higher education: A great driving force for Beijin-Tianjin-Hebei integration, J. China Higher Education, vol.23, pp. 15-17, 2015.

[6] Zuliang Liu, Research of development policy about university clusters of megalopolis: Basing on the goal to build stronger national tertiary education, D. Beihang University, 2011.

[7] Zhanhui Sun, Regional resource sharing of higher education: Connotation, concept and mechanism, J. Journal of Social Science of Harbin Normal University, vol.5, pp.138-142, 2012.

[8] The Editorial Office, Reform and development of open universities: Reflection and prospect, J. Open Education Research, vol.2, pp. 4-16, 2016.

[9] Wenhua Ye, Open university: Theoretical guide, path selection and institutional innovation, J. Modern Distance Education, vol.4, pp.7-9, 2011. 